\author{
H. Chakir • D. E. Lefebvre $\cdot$ H. Wang $\cdot$ E. Caraher $\cdot$ \\ F. W. Scott
}

\title{
Wheat protein-induced proinflammatory $T$ helper 1 bias in mesenteric lymph nodes of young diabetes-prone rats
}

Received: 18 November 2004 / Accepted: 23 March 2005 / Published online: 8 July 2005

C) Springer-Verlag 2005

\begin{abstract}
Aims/hypothesis: Type 1 diabetes is the result of an inflammatory T helper 1 (Th1) lymphocyte-mediated beta cell destructive process. The majority of diabetesprone BioBreeding (BBdp) rats fed wheat protein-based diets, such as NTP-2000, develop type 1 diabetes and display a mild coeliac-like enteropathy. Mesenteric lymph nodes (MLNs), which drain the gut, are the major inductive site where dietary antigens are recognised in the gut-associated lymphoid tissue (GALT). We hypothesised that this compartment could be a site of abnormal wheat proteininduced Th1 cell activation. Methods: MLN cells were isolated from $\mathrm{BBdp}$ and $\mathrm{BB}$ control $(\mathrm{BBc})$ rats that were fed NTP-2000 or a hydrolysed casein (HC)-based diet at ages that pre-date classic insulitis. The inflammatory status, phenotype and proliferation of these cells in response to wheat protein were determined. Results: The expression ratio of T-bet : Gata3, master transcription factors for Th1 and Th2 cytokines, was increased in the MLN from NTP2000 -fed BBdp rats compared with that from $\mathrm{BBc}$ rats, mainly due to decreased Gata 3 expression. $\mathrm{CD}^{+} \mathrm{CD}^{+}$ IFN $-\gamma^{+}$T cells were more prevalent in the MLN of wheatfed BBdp rats, but remained at control levels in BBdp rats fed a diabetes-retardant $\mathrm{HC}$ diet. BBdp MLN cells proliferated in response to wheat protein antigens in a specific, dose-dependent manner, and $>93 \%$ of cells were $\mathrm{CD}^{+}$ $\mathrm{CD}^{+} \mathrm{T}$ cells. This proliferation was associated with a low proportion of $\mathrm{CD} 4{ }^{+} \mathrm{CD} 25^{+} \mathrm{T}$ cells and a high proportion of
\end{abstract}

H. Chakir · D. E. Lefebvre - H. Wang - E. Caraher ·

F. W. Scott $(\bowtie)$

Molecular Medicine,

Ottawa Health Research Institute,

501 Smyth Road,

Ottawa, ON K1H 8L6, Canada

e-mail: fscott@ohri.ca

Tel.: +1-613-737-8929

Fax: +1-613-739-6189

D. E. Lefebvre · F. W. Scott

Department of Biochemistry,

Microbiology and Immunology,

University of Ottawa,

Ottawa, ON, Canada dendritic cells in the MLN of BBdp rats. Conclusions/ interpretation: Before insulitis is established, the MLNs of wheat-fed BBdp rats contain an unusually high proportion of Th1 cells that proliferate specifically in response to wheat protein antigens.

Keywords BioBreeding (BB) rat · Diet - Environment · Gut $\cdot$ IFN- $\gamma \cdot$ Type 1 diabetes $\cdot$ Wheat

Abbreviations BBc: BioBreeding control - BBdp: diabetes-prone BioBreeding - CFDA-SE: 5,6carboxyfluorescein diacetate succinimidyl ester - FITC: fluorescein isothiocyanate - GALT: gut-associated lymphoid tissue - Gata-3: GATA binding protein-3 - HC: diabetes-retardant AIN-93G hydrolysed casein-based diet . mAb: monoclonal antibody $\cdot$ MLN: mesenteric lymph node - NOD: non-obese diabetic - NTP-2000: diabetespromoting, wheat-based diet - OVA: chicken ovalbumin . PE: phycoerythrin - PMA: phorbol 12-myristate 13acetate $\cdot$ T-bet: T-box expressed in T cells $\cdot$ TCR: T cell receptor - Th1: T helper $1 \cdot \mathrm{Th} 2: \mathrm{T}$ helper 2

\section{Introduction}

Type 1 diabetes develops as a result of poorly understood interactions among several risk genes and environmental stimuli, including dietary proteins $[1,2]$. Approximately two-thirds of diabetes-prone BioBreeding (BBdp) rats from the Ottawa colony fed a defined wheat-based diet (NTP2000) [3] develop type 1 diabetes between 65 and 130 days, whereas only $20-25 \%$ of BBdp rats fed a protective hydrolysed casein-based AIN-93G (HC) diet become diabetic [4]. Diabetes in non-obese diabetic (NOD) mice is also associated with wheat $[1,5-7]$. Early exposure to cereals including wheat was the factor most strongly associated with the development of islet autoantibodies in two recent prospective studies in children at high risk of developing type 1 diabetes $[8,9]$. A large multicentre prospective study, the Trial to Reduce the Incidence of Type 1 Diabetes in the Genetically at Risk (TRIGR), was launched 
recently to investigate the effect of delayed exposure to intact food proteins in high-risk infants. Our group recently identified a wheat storage globulin-like protein as a candidate diabetes-related antigen in diabetic rats and human patients [4]. There is evidence that the gut is mildly inflamed and abnormally permeable to lumen antigens in BBdp rats [10-14] and in human patients with type 1 diabetes [15-18]. However, remarkably little is known about the immune state of the gut-associated lymphoid tissue (GALT) in animals or humans that spontaneously develop type 1 diabetes.

The gut of diabetes-prone rats may be a reservoir of $\mathrm{T}$ helper 1 (Th1) lymphocytes that can be stimulated to proliferate by antigens from a diabetes-promoting, wheatbased diet. To investigate this, we compared the Th1/Th2 status, phenotype and proliferation of mesenteric lymph node (MLN) cells from BioBreeding control (BBc) rats and BBdp rats.

\section{Materials and methods}

Experimental design Three separate cross-sectional studies (Table 1) were performed. First, we analysed tissues from NTP-2000-fed rats aged 30 days for expression of the genes encoding T-bet (now known as T-box 21) and GATA binding protein 3 (Gata-3), transcription factors that control Th1 and Th2 cytokine expression [19]. In a second set of experiments, $\mathrm{BBc}$ and BBdp rats were fed either the HC or NTP-2000 diet to age 45 days to ensure full Th1 polarisation of naïve T cells [19], and then MLN cells were analysed for the presence of IFN $-\gamma^{+}$Th1 cells using intracellular flow cytometry [20]. Both these analyses indicated a Th1 bias in the gut of young, pre-insulitic (NTP-2000-fed) BBdp rats. Therefore, in a third set of experiments, we determined whether wheat-specific $\mathrm{T}$ cells were still present and which immune cells characterised the MLN at around age 60 days, a critical time point when NTP-2000-fed BBdp rats begin to develop diabetes.

Animals, diets and preparation of wheat protein digest $\mathrm{BBdp}$ rats and non-diabetes-prone $\mathrm{BBc}$ rats of both sexes were obtained from the Animal Resources Division of Health Canada (Ottawa, ON, Canada). The animals were kept under specific pathogen-free conditions. At 23 days, animals were weaned and given free access to a diabetespromoting, wheat-based NTP-2000 diet, or a diabetes-retar- dant $\mathrm{HC}$ diet. At the indicated ages, rats were exsanguinated while under anaesthesia with $3 \%$ isoflurane in oxygen. Tissues were removed and then either analysed immediately or used to prepare single cell suspensions. Animal use was approved by the local animal care committee.

The wheat protein extract was made from wheat gluten (ICN Biochemicals, Cleveland, OH, USA) digested and solubilised with 100:1 (w/w) $\alpha$-chymotrypsin (Sigma, Oakville, ON, Canada) in $174 \mathrm{mmol} / \mathrm{l}$ Tris base, $\mathrm{pH} 7.8$, overnight at $37^{\circ} \mathrm{C}$, as previously described [21]. The digested wheat protein was centrifuged at $1,500 \mathrm{~g}$ for $15 \mathrm{~min}$ at $22^{\circ} \mathrm{C}$ and then filtered through a $0.2 \mu \mathrm{m}$ Acrodisc filter (Millipore, Billerica, MA, USA). Protein concentration was determined using the Bradford assay [22].

Cytokines, antibodies and reagents Phorbol 12-myristate 13-acetate (PMA), ionomycin, propidium iodide and FBS were from Sigma. Recombinant human IL-2 was a gift from C. Reynolds (National Institutes of Health, Bethesda, MD, USA). We obtained 5,6-carboxyfluorescein diacetate succinimidyl ester (CFDA-SE) from Molecular Probes (Burlington, ON, Canada). Phycoerythrin (PE)-conjugated CD25 (OX39) and biotinylated mouse anti-rat OX-62 (MRC OX-62) were from Serotec (Raleigh, NC, USA). PE-conjugated rat CD45RA (OX-33), which recognises a $\mathrm{B}$ cell-specific isoform of rat CD45, and ECD-conjugated streptavidin were from Immunotech-Coulter (Marseille, France). PE-conjugated anti-rat $\alpha \beta$ T cell receptor (TCR) monoclonal antibody (mAb) (R73) was from Cedarlane (Hornby, ON, Canada). Purified mouse anti-rat CD3 mAb (G4.18), purified mouse anti-rat CD28 mAb (JJ319), CyChrome-conjugated anti-rat $\mathrm{CD} 4 \mathrm{mAb}(\mathrm{OX}-35)$, FITCconjugated mouse anti-rat CD8b mAb (341), PE-conjugated anti-rat macrophage subset mAb (HIS36), FITC-conjugated mouse anti-rat CD3 (G4.18), PE-conjugated mouse IgG1 $\mathrm{K}$ isotype control (MOPC-21), RiCK-2 positive control cells, Cytofix/Cytoperm Kit and GolgiPlug were from BD Pharmingen (San Diego, CA, USA). FITC-conjugated Perm-a-Sure permeabilisation control antibody, and PEconjugated anti-rat IFN- $\gamma$ (DB-1) were obtained from Biosource (Camarillo, CA, USA). RPMI 1640, PBS, Lglutamine, penicillin and streptomycin were purchased from Invitrogen (Burlington, ON, Canada).

Experiment 1: expression of T-bet and Gata-3 genes in whole tissues MLNs were excised aseptically from 30day-old BBc and BBdp rats fed NTP-2000, homogenised

Table 1 Experimental groups

\begin{tabular}{|c|c|c|c|c|c|c|c|c|}
\hline \multirow[b]{2}{*}{ Animal } & \multicolumn{2}{|c|}{$\begin{array}{l}\text { Experiment 1: T-bet : } \\
\text { Gata3 expression ratio }\end{array}$} & \multicolumn{4}{|c|}{$\begin{array}{l}\text { Experiment 2: frequency } \\
\text { of Th1 cells }\end{array}$} & \multicolumn{2}{|c|}{$\begin{array}{l}\text { Experiment 3: wheat } \\
\text { protein-specific } \mathrm{T} \text { cell } \\
\text { phenotype }\end{array}$} \\
\hline & $\mathrm{BBc}$ & BBdp & $\mathrm{BBc}$ & $\mathrm{BBc}$ & BBdp & BBdp & $\mathrm{BBc}$ & BBdp \\
\hline Number of rats per group & 5 & 5 & 5 & 9 & 7 & 8 & 6 & $5-6$ \\
\hline Diet & NTP-2000 & NTP-2000 & $\mathrm{HC}$ & NTP-2000 & $\mathrm{HC}$ & NTP-2000 & NTP-2000 & NTP-2000 \\
\hline Mean age at kill & 30 days & & 45 days & & & & 60 days & \\
\hline
\end{tabular}


in TRIzol reagent (Invitrogen, Burlington, ON, Canada), and total RNA was isolated for RT-PCR. Gene expression was analysed using semi-quantitative RT-PCR, with $\beta$ actin used as an internal control. Reverse transcription was carried out with total RNA using an oligo(dT) $)_{16}$ primer and a GeneAmp RNA PCR Kit (Roche, Mississauga, ON, Canada). PCR was performed using the GeneAmp PCR kit, and DMSO was used to enhance the reaction. PCR products were separated by electrophoresis through a $1.5 \%$ agarose gel, and the net band intensity was analysed using a Kodak Image Station 440CF (Eastman Kodak, Rochester, NY, USA). PCR cycle number was optimised as described previously [19]. The absence of genomic DNA contamination was confirmed by performing PCR without reverse transcription amplification of mRNA. Primers targeting T-bet were designed using the sequence of the gene encoding T-bet outside the T-box domain in the mouse [23] to maintain their specificity for T cells. Primers targeting the genes encoding GATA-3 (Gata3) and $\beta$-actin $(A c t b)$ were designed using rat gene sequences. The sequences of the primers used were as follows: T-bet: sense 5'-AACCAGTATCCTGTTCCCAGC-3', antisense 5'-TGT CGCCACTGGAAGGATAG-3'; Gata3: sense 5'-CTCTC CTTTGCTCACCTTTTC-3', antisense 5'-AAGAGATGC GGACTGGAGTG-3'; Actb: sense: 5'-CCAGCCTTCCTT CCTGGGTA-3', antisense: 5'-CTAGAAGCATTTGCGGT GCA-3'. A PCR annealing temperature of $58^{\circ} \mathrm{C}$ was used for the primers targeting T-bet and Gata3, and a temperature of $55^{\circ} \mathrm{C}$ was used for those targeting $A c t b$. The size of the PCR product was $436 \mathrm{bp}, 619 \mathrm{bp}$ and $343 \mathrm{bp}$ for T-bet, Gata3 and Actb, respectively.

Experiment 2: flow cytometry analysis of IFN- $\gamma$ in freshly isolated T cells Single cell suspensions of freshly isolated MLN and spleen cells were prepared, as described previously [20], from 45-day-old $\mathrm{BBc}$ and $\mathrm{BBdp}$ rats fed either an HC or NTP-2000 diet. Cells were cultured in vitro in 6-well culture plates (Falcon, Lincoln Park, NJ, USA) at a concentration of $2 \times 10^{6}$ cells $/ \mathrm{ml}$ in RP- 10 medium, consisting of RPMI 1640 medium supplemented with $10 \%(\mathrm{v} / \mathrm{v})$ heat-inactivated FBS, $2.0 \mathrm{mmol} / \mathrm{l} \mathrm{L-glu-}$ tamine, $50 \mathrm{mmol} / 1$ 2-mercaptoethanol, $100 \mathrm{U} / \mathrm{ml}$ penicillin and $100 \mu \mathrm{g} / \mathrm{ml}$ streptomycin. Cells were stimulated with $50 \mathrm{ng} / \mathrm{ml} \mathrm{PMA}$ and $1 \mu \mathrm{g} / \mathrm{ml}$ ionomycin in the presence of $1 \mu \mathrm{g} / \mathrm{ml}$ brefeldin A (GolgiPlug) for $6 \mathrm{~h}$ at $37^{\circ} \mathrm{C}, 5 \% \mathrm{CO}_{2}$. Cells were surface stained with anti-CD3-FITC and antiCD4-Cy-Chrome antibodies for $10 \mathrm{~min}$, and then washed with $2 \mathrm{ml}$ of Isoton (Beckman Coulter, Mississauga, ON, Canada) at $4^{\circ} \mathrm{C}$. Cells were fixed and permeabilised using Cytofix/Cytoperm for $10 \mathrm{~min}$ at $4^{\circ} \mathrm{C}$, washed with $1 \times$ Perm/Wash, and then incubated with PE-conjugated mouse anti-rat IFN- $\gamma$ or PE-conjugated mouse IgG1 $\mathrm{K}$ isotype control for $30 \mathrm{~min}$ at $4^{\circ} \mathrm{C}$. Cells were washed with $1 \times \mathrm{Perm} /$ Wash at $4^{\circ} \mathrm{C}$ and resuspended in Isoton. $\mathrm{CD}^{+} \mathrm{CD} 4^{+}$cells were analysed for intracellular IFN- $\gamma$ as described previously [20]. Isotype controls were used to determine nonspecific binding.
Experiment 3: measurement of the proliferation of immune cells in response to wheat protein antigens using CFDA$S E$ labelling A CFDA-SE-based proliferation assay [24] was used to analyse the wheat protein reactivity of $\mathrm{CD} 4^{+} \mathrm{T}$ cells from MLNs and spleens from 60-day-old BBc and BBdp rats fed an NTP-2000 diet. Briefly, MLN and spleen cells were isolated, resuspended in sterile PBS at a concentration of $20 \times 10^{6}$ cells $/ \mathrm{ml}$, and then stained with 5 $\mu \mathrm{mol} / \mathrm{l} \mathrm{CFDA-SE}$ for $20 \mathrm{~min}$ at $37^{\circ} \mathrm{C}$. Stained cells were washed with RP-10 medium, resuspended to provide a final concentration of $2 \times 10^{6}$ cells $/ \mathrm{ml}$, and cultured with $\alpha$ chymotrypsin-treated wheat protein or control antigens in 12-well plates for 3-7 days. Cells cultured in medium alone or in the presence of chicken egg white ovalbumin (OVA) protein (Sigma) served as negative controls. As a positive control for proliferation, cells were cultured in the presence of $5 \mu \mathrm{g} / \mathrm{ml}$ plate-bound anti-CD3 $\mathrm{mAb}$ and 1 $\mu \mathrm{g} / \mathrm{ml}$ soluble anti-CD28 mAb. At 3 and 7 days after stimulation, cells were harvested and stained with $\mathrm{Cy}$-Chromeconjugated anti-rat CD4 and PE-conjugated anti-rat $\alpha \beta$-TCR $\mathrm{mAbs}$ for flow cytometric analysis with an FC500 flow cytometer (Beckman-Coulter, Mississauga, ON, Canada). Proliferating cells lose CFDA-SE fluorescence and exhibit a CD4 ${ }^{+}$CFDA-SE ${ }^{\text {low }}$ phenotype, while non-dividing cells display a $\mathrm{CD} 4^{+} \mathrm{CFDA}-\mathrm{SE}{ }^{\text {high }}$ phenotype. Data on the response to antigen are reported as the ratio of $\mathrm{CD}^{+} \mathrm{CFDA}-\mathrm{SE}^{\text {low }}$ : total $\mathrm{CD} 4^{+}$cells analysed. $\mathrm{CD} 4^{+}$MLN cells proliferating in response to wheat protein antigens $\left(\mathrm{CD} 4^{+} \mathrm{CFDA}-\mathrm{SE}^{\text {low }}\right)$ were analysed for expression of $\alpha \beta$-TCR, a specific marker of $\mathrm{CD}^{+} \mathrm{T}$ cells. Dead cells were excluded from the analysis by gating on propidium iodide-negative cells.

Characterisation of the phenotype of MLN and spleen cells The surface marker phenotype of MLN and spleen cells from the 60-day-old rats was established using flow cytometry. Cells were stained for $\alpha \beta$-TCR, CD4, CD $8 b$, CD45RA, HIS-36 and OX-62 to determine the frequency of $\mathrm{CD}^{+}, \mathrm{CD}^{+}, \mathrm{CD}^{+}{ }^{+} \mathrm{T}$ cells, $\mathrm{B}$ cells, macrophages and dendritic cells, and were co-stained for CD4 and CD25 to identify surface markers for regulatory/activated $\mathrm{T}$ cells. At least $2 \times 10^{4}$ events were analysed.

Statistical analyses One-way ANOVA (with least significant difference post hoc analysis where appropriate) was performed to determine the significance of differences between means. A $p$ value less than 0.05 was considered significant.

\section{Results}

Experiment 1: increased T-bet: Gata3 expression ratio in the MLN of young BBdp rats The T-bet: Gata 3 expression ratio of fresh tissue reflects the in vivo Th1/Th2 microenvironment [19]. Therefore, we analysed the expression of T-bet and Gata3 in freshly isolated MLN tissues of BBc and BBdp rats fed an NTP-2000 diet. At 30 days of age, 1 


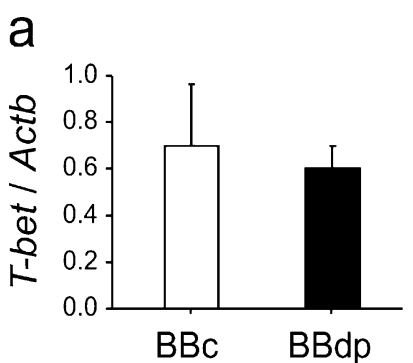

Fig. 1 T-bet : Gata3 ratio in MLN. Expression of T-bet (a), Gata3 (b) and the T-bet: Gata3 ratio (c) measured by semi-quantitative RTPCR in 30-day-old NTP-2000-fed BBc (open bars) and BBdp rat

week after weaning and approximately 5 weeks before diabetes cases begin to appear, the MLN of BBdp rats had a higher T-bet : Gata3 expression ratio than the MLN of $\mathrm{BBc}$ rats $(p<0.05, n=5$ per group; Fig. 1$)$, indicating a predisposition towards a Th1 phenotype (for details refer
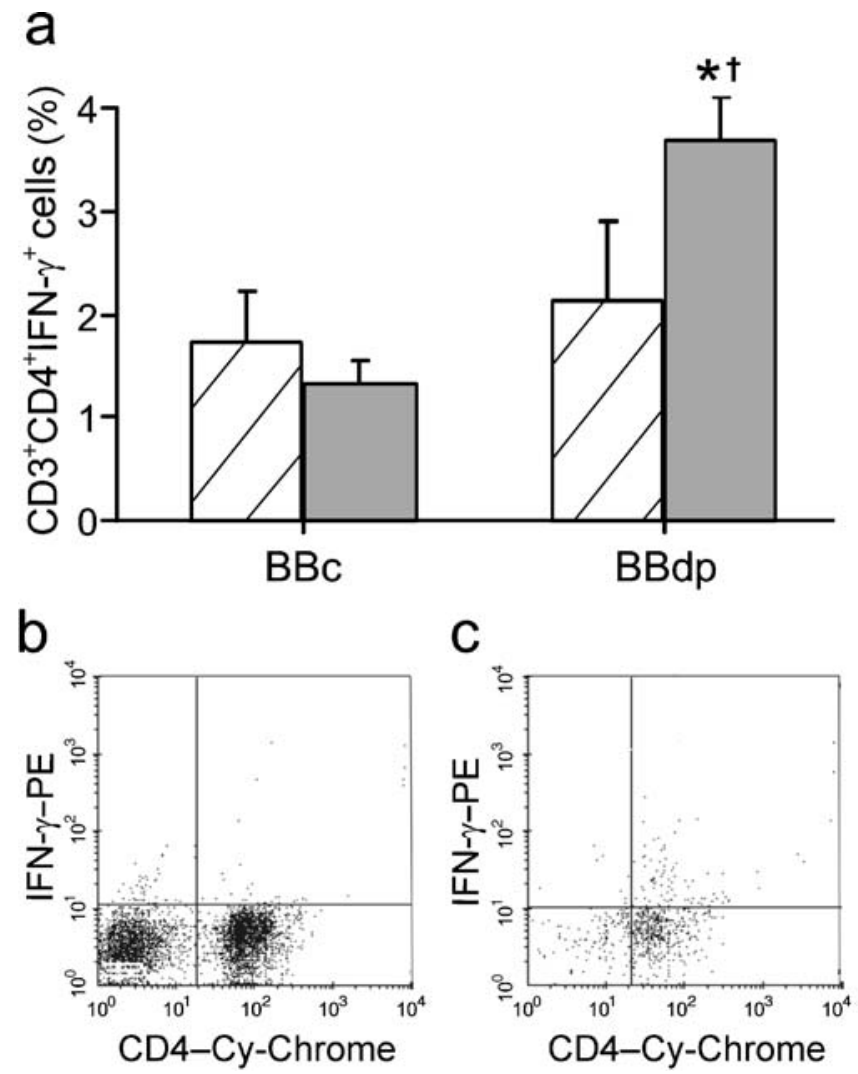

Fig. 2 Dietary modification of the frequency of $\mathrm{CD} 3^{+} \mathrm{CD} 4^{+} \mathrm{IFN}-\gamma^{+}$ MLN cells. a MLN cells were isolated from HC-fed (hatched bars) and NTP-2000-fed (grey bars) 45-day-old BBc rats $(n=5-9$ per group) and $\mathrm{BBdp}$ rats $(n=7-8$ per group) and then stimulated in vitro with PMA and ionomycin for $6 \mathrm{~h}$. Samples were surface stained for CD3 and CD4, fixed, permeabilised, stained with PEconjugated mouse anti-rat IFN- $\gamma$, and then analysed by flow cytometry. b, c Two-colour dot plots of $\mathrm{CD} 4^{+} \mathrm{IFN}-\gamma^{+}$cells from MLN were generated after gating on $\mathrm{CD}^{+}$cells to correct for the lymphopenia. Representative plots are shown for NTP-2000-fed BBc (b) and BBdp (c) rats. Data are expressed as mean percentages of $\mathrm{CD}^{+}$ $\mathrm{CD} 4{ }^{+} \mathrm{IFN}-\gamma^{+}$cells \pm SEM. ${ }^{*} p<0.005$ vs $\mathrm{BBc}$ rats; ${ }^{\dagger} p<0.05$ vs $\mathrm{HC}-$ fed BBdp rats

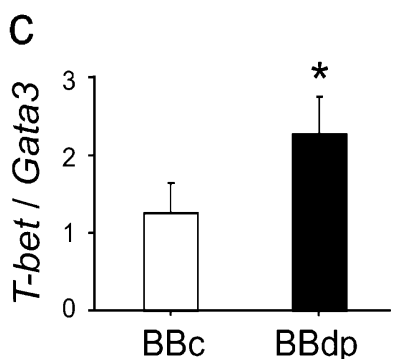

(filled bars) MLN immediately upon excision of the tissue ( $n=5$ per group). Data were normalised to the expression of the gene encoding $\beta$-actin $(A c t b)$ and represent means $\pm \mathrm{SD}$. ${ }^{*} p<0.05$ vs BBc rats

to [19]). Peyer's patches showed essentially the same pattern (data not shown). The increased T-bet: Gata3 ratio was attributable to decreased Gata3 expression rather than increased expression of T-bet. There was no difference in the T-bet : Gata3 expression ratio in the MLN of NTP2000 -fed rats at 23 days, which corresponds to the first day after weaning (data not shown).

Experiment 2: increased frequency of $\mathrm{CD}^{+} \mathrm{IFN}^{-} \gamma^{+} \mathrm{T}$ cells in the MLN of NTP-2000-fed BBdp rats $\mathrm{CD} 4^{+}$Th1 cells play a major role in diabetes pathogenesis in the BBdp rat [25-28]. To determine whether the early Th1/Th2 imbalance would be reflected as an increased frequency of Th1 cells in the GALT, $\mathrm{CD} 4^{+}$T cells were quantified for IFN- $\gamma$ production using surface markers and intracellular flow cytometry [20] (Fig. 2). This approach compensates for the confounding effects of $\mathrm{T}$ cell lymphopenia in BBdp rats. Consistent with the gene expression data, the frequency of $\mathrm{CD} 3^{+} \mathrm{CD} 4^{+} \mathrm{IFN}-\gamma^{+}$cells was approximately three times higher in the MLN from 45-day-old NTP-2000-fed BBdp rats than in the MLN from BBc rats $(p=0.001, n=8-9$ per group; Fig. 2a). The $\mathrm{CD}^{+} \mathrm{CD}^{+} \mathrm{IFN}-\gamma^{+}$cells were present at control levels in the MLN from BBdp rats fed an HC $\operatorname{diet}\left(p=0.03, n=7-8\right.$ per group; Fig. $2 \mathrm{a}$ ). Dot plots of $\mathrm{CD} 4^{+}$ IFN $-\gamma^{+} \mathrm{T}$ cells from representative $\mathrm{BBc}$ and BBdp rats fed the NTP-2000 diet are shown in Fig. 2b and c. The frequency of $\mathrm{CD}^{+} \mathrm{CD} 4^{+} \mathrm{IFN}-\gamma^{+}$cells in the spleen was not affected by diet in either $\mathrm{BBc}$ or BBdp rats (data not shown), which suggests that the gut is a specific site for the dietary activation of Th1 cells.

Experiment 3: reactivity of $C D 4^{+} T$ cells from the MLN of $N T P-2000-f e d B B d p$ rats to wheat protein antigens in vitro In a further experiment, we investigated whether wheatreactive $T$ cells were present around the critical time when BBdp rats begin to develop diabetes ( $\sim 60$ days). The proliferation of MLN cells in response to various concentrations of wheat protein was evaluated in vitro (Fig. 3). MLN and spleen cells from BBdp and BBc rats that had been exposed to the NTP-2000 diet for 5 weeks were stained with CFDA-SE and incubated in vitro in the absence or presence of varying concentrations of $\alpha$-chymotrypsin-treated wheat protein $(12.5,25$ and $50 \mu \mathrm{g} / \mathrm{ml})$. As controls, cells were incubated in the presence of OVA protein or with anti-CD3 plus anti-CD28 mAbs. Little or 
Fig. 3 Proliferation of MLN and spleen cells in response to wheat protein antigens. Cells from the MLN (a) or spleen (b) of 60-day-old NTP-2000-fed $\mathrm{BBc}$ (open bars) and BBdp (filled bars) rats ( $n=6$ per group) were stained with CFDA-SE and plated in the absence (medium only) or presence of increasing concentrations of wheat protein (WP, $\mu \mathrm{g} / \mathrm{ml}$ ). Control cultures contained OVA protein or anti-CD3 and anti-CD28 mAbs. At day 3 , cells were stained with anti-rat CD4 antibody and then cell proliferation was analysed by flow cytometry. Bars represent means \pm SD of the ratio of proliferating $\mathrm{CD} 4{ }^{+}$cells to total $\mathrm{CD}^{+}$cells. ${ }^{*} p<0.05$ vs $\mathrm{BBc}$ rats. c To determine the phenotype of the wheat proteinreactive MLN cells, CFDA-SElabelled MLN cells from 60-day-old NTP-2000-fed BBdp rats were cultured for 7 days in the presence of $50 \mu \mathrm{g} / \mathrm{ml}$ wheat protein and then stained with anti-CD4 and anti- $\alpha \beta$-TCR mAbs. $\mathrm{CD}^{+}$MLN cells proliferating to wheat protein antigens (CD4 $4^{+}$CFDA-SE ${ }^{\text {low }}$ ) were gated (open box) and analysed by flow cytometry to assess levels of $\alpha \beta-\mathrm{TCR}^{+}$cells

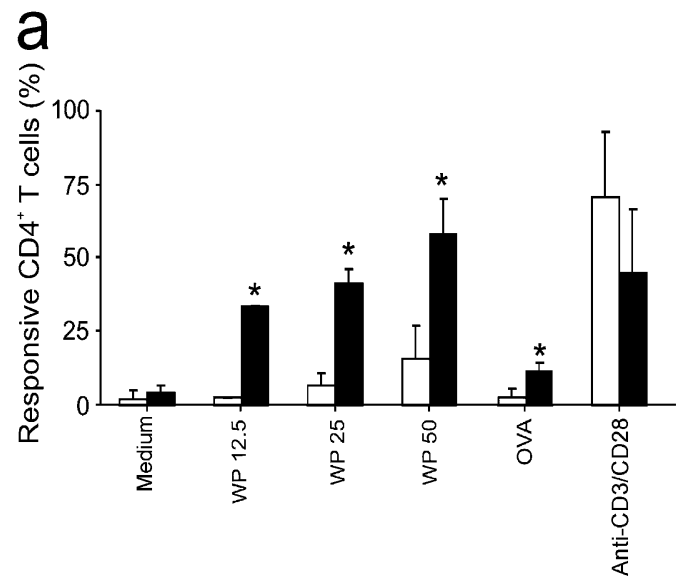

b

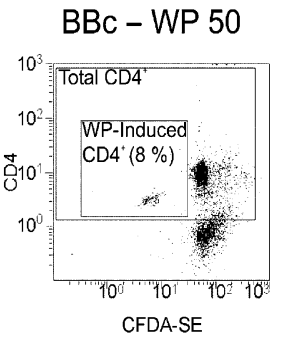

BBdp - WP 50

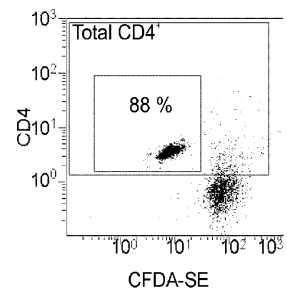

C

$\mathrm{BBc}-$ WP 50

BBdp - WP 50
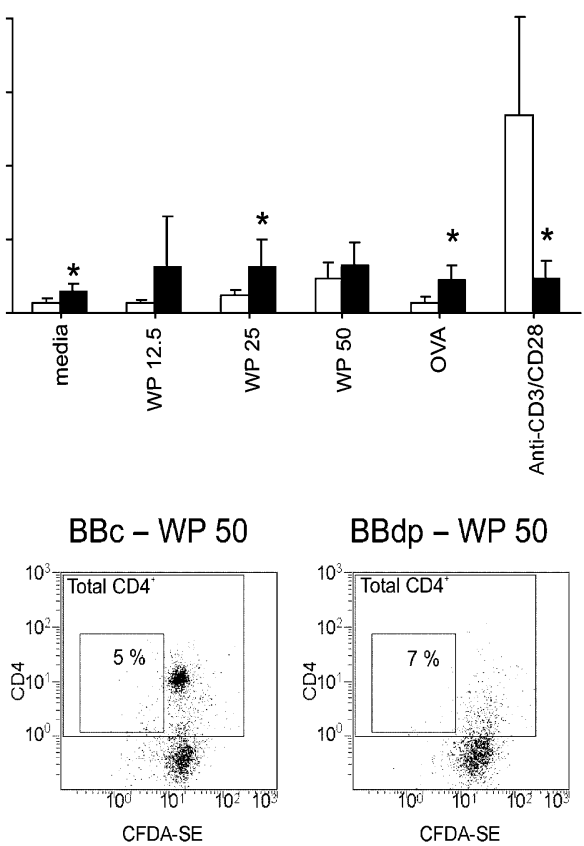

CFDA-SE

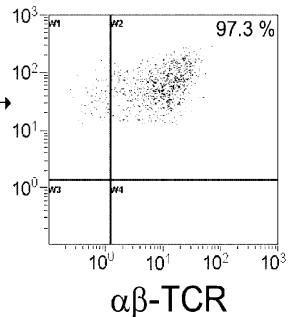

no cell proliferation was detected in the absence of wheat protein antigens or in the presence of OVA protein. The MLN cells from $\mathrm{BBc}$ and $\mathrm{BBdp}$ rats proliferated in response to stimulation with anti-CD3 plus anti-CD28 mAbs. We observed that $\mathrm{CD}^{+}$MLN cells from BBdp rats proliferated specifically in a dose-dependent manner in response to wheat protein antigens (Fig. 3a), whereas CD4 ${ }^{-}$MLN cells did not respond to wheat proteins. Compared with those from $\mathrm{BBc}$ rats, $\mathrm{CD}^{+}$MLN cells from BBdp animals showed significantly greater cell proliferation in response to wheat pro-

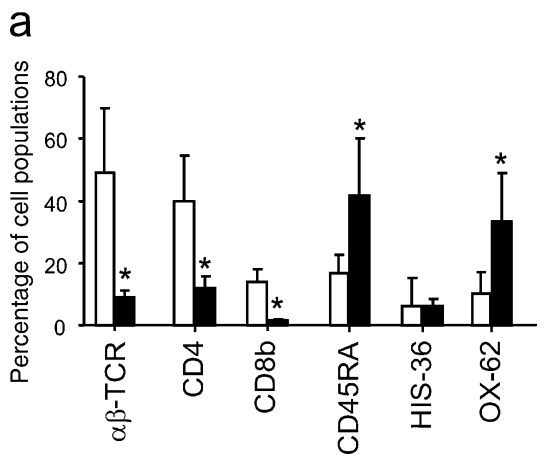

Fig. 4 Phenotype of MLN and spleen cells. Freshly isolated MLN cells (a) or spleen cells (b) from 60-day-old NTP-2000-fed BBc (open bars, $n=6$ ) and BBdp (filled bars, $n=5$ ) rats were stained with antibodies specific for rat CD3 ( $\alpha \beta$-TCR), CD4, CD8, macrophage b

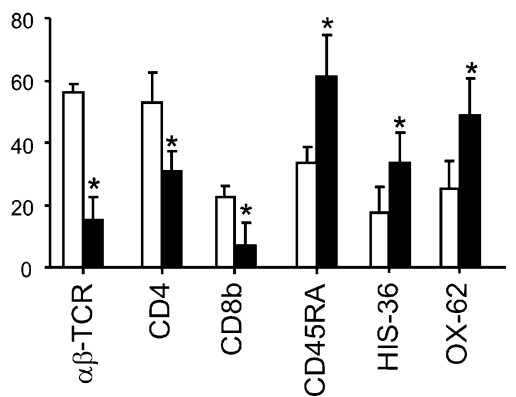

(His-36), B cell (CD45RA) or dendritic cell (OX-62) surface markers and the percentage of cells expressing these markers was analysed by flow cytometry. Data represent means \pm SD. ${ }^{*} p<0.05$ vs $\mathrm{BBc}$ rats 
tein antigens ( $p<0.05, n=6$ per group; Fig. 3a). In BBdp rats, the proliferation of cells in response to wheat protein antigens was greater in the gut-associated MLN than in the spleen (Fig. 3b). This finding can probably be explained by the presence of inhibitory macrophages that make up a significantly greater proportion of the cell population in the spleen (Fig. 4) [29]. In rats, CD4 is expressed on T lymphocytes as well as on the cell surface of monocytes and macrophages. The phenotype of the wheat protein-reactive cells was determined by staining with anti-rat CD4 and anti-rat $\alpha \beta$-TCR (CD3) mAbs. By gating on CD4 ${ }^{+}$CFDA$\mathrm{SE}^{\text {low }}$ cells (wheat protein-reactive cells), we found that 93-97\% of the wheat protein-reactive $\mathrm{CD}^{+}$cells expressed the $\mathrm{CD}^{+} \mathrm{T}$ cell-specific marker, $\alpha \beta$-TCR; further confirming that the response to wheat protein in the MLN of BBdp rats was mediated by $\mathrm{CD} 3^{+} \mathrm{CD} 4^{+} \mathrm{T}$ cells (Fig. $3 \mathrm{c}$ ).

Increased antigen-presenting cells and decreased $C D 4^{+}$ $C D 25^{+} T$ cells in BBdp rats To further characterise the cell populations, we used flow cytometry to analyse the phenotype of freshly isolated MLN and spleen cells from NTP-2000-fed BBc and BBdp rats aged 60 days. The characteristic lymphopenia in BBdp rats resulted in low numbers of $\mathrm{CD}^{+}\left(\alpha \beta-\mathrm{TCR}^{+}\right.$cells $), \mathrm{CD}^{+}$and $\mathrm{CD}^{+}$ $\left(\mathrm{CD} 8 \mathrm{~b}^{+}\right.$cells) $\mathrm{T}$ cells in the MLN (Fig. 4a) and spleen (Fig. 4b). Compared with those of BBc rats, the MLN and spleen from BBdp rats contained a higher frequency of dendritic cells $\left(\mathrm{OX}-62^{+}\right.$cells) and $\mathrm{B}$ cells $\left(\mathrm{CD} 45 \mathrm{RA}^{+}\right.$cells). Furthermore, macrophage frequency (HIS- $36^{+}$cells) in the spleen was significantly higher in BBdp rats than in BBc animals (Fig. 4b). The data show that lymphopenia in BBdp rats is associated with a high frequency of antigenpresenting cells, such as B lymphocytes and dendritic cells, in the MLN and spleen, increasing the potential for antigen presentation and the induction of $\mathrm{T}$ cell proliferation. In addition, compared with those from healthy $\mathrm{BBc}$ animals, the MLN and spleen from BBdp rats showed a significantly lower frequency of cells with a $\mathrm{CD} 4{ }^{+} \mathrm{CD} 25^{+}$regulatory $\mathrm{T}$ cell phenotype ( $p<0.05, n=5-6$ per group; Fig. 5 ).
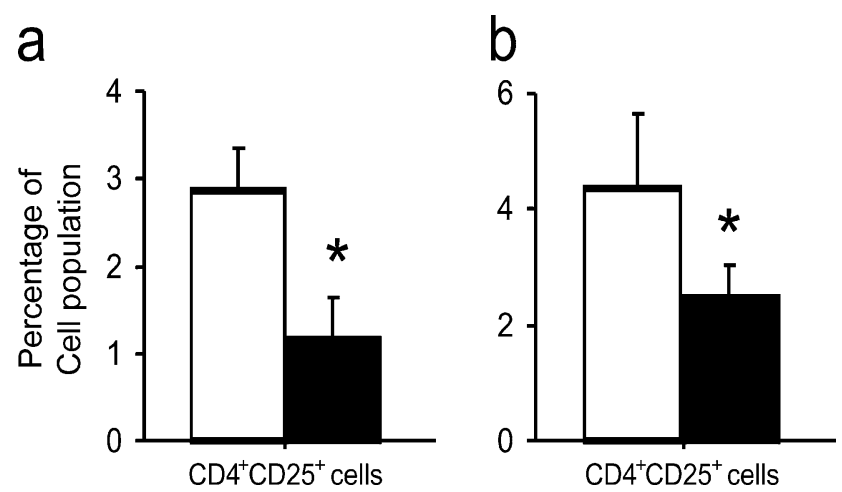

Fig. $5 \mathrm{CD} 4{ }^{+} \mathrm{CD} 25^{+}$regulatory T cells in MLN and spleen. Freshly isolated MLN cells (a) or spleen cells (b) from 60-day-old NTP2000 -fed BBc (open bars, $n=6$ ) and BBdp (filled bars, $n=5$ ) rats were stained with antibodies specific for regulatory $\mathrm{T}$ cell surface markers (CD4 and CD25) and the percentage of cells expressing these markers was analysed by flow cytometry. Data represent the means \pm SD of the percentage cell population. ${ }^{*} p<0.05$ vs BBc rats

\section{Discussion}

Type 1 diabetes is a complex, multifactorial disease that is strongly influenced by environmental factors, including diet, in genetically susceptible individuals $[1,2,4,26]$. Wheat gluten is a concentrated mixture of wheat proteins that is associated with the development of type 1 diabetes in BBdp rats $[4,30,31]$ and NOD mice [5-7, 54]. Feeding nutritionally comparable semipurified diets in which wheat gluten was either the major or the sole protein source to BBdp rats produced nearly three times as many cases of type 1 diabetes and higher insulitis rating compared with $\mathrm{HC}$-fed rats $(p<0.001)$ [4]. Even under strict germ-free conditions, BBdp rats still develop diabetes when fed an irradiated wheat-based diet, whereas HC-fed BBdp rats are almost completely protected (F. W. Scott, unpublished data). This suggests that diet has a major effect on the development of diabetes in BBdp rats.

The inflammation in the pancreas that destroys islet beta cells is predominantly a Th1 process, which is characterised by the production of IFN- $\gamma$ in BBdp rats [25-28] and in humans [32]. However, the origin of these Th1 cells, the stimulatory antigens, and the timing and circumstances under which the cells become activated remain unclear. The gut has been proposed as a possible source of these cells $[31,33,34]$, but information on the inflammatory status of the gut, the identity of the cells and the possible stimulatory dietary antigens encountered during the period before the development of overt diabetes is lacking.

Thus, our understanding of the role of the gut in diabetes pathogenesis and its modification by diet is rudimentary, particularly in humans, where studies of the gastrointestinal tract are difficult and few $[15,35,36]$. The pioneering studies by Westerholm-Ormio et al. revealed the increased production of IFN- $\gamma$ and other proinflammatory markers consistent with a Th1 condition in the jejunal mucosa of patients [15]. However, because the inductive tissues of the GALT are not readily accessible in humans, they have not been studied in prediabetic or diabetic individuals. The results of the present study of the pre-insulitis period are consistent with the findings of Westerholm-Ormio et al. and suggest that, in the major inductive site of the gut, the MLN, a Th1 bias exists as early as 1 week after weaning.

MLNs are gut-associated secondary lymphoid organs in which an adaptive immune response to antigens encountered in the gut lumen occurs [37]. MLNs are crucial centres where presentation of soluble dietary antigens to naïve $T$ cells occurs, either by uptake of the antigen by resident antigen-presenting cells or via antigen-presenting cells that transport the antigen to the MLN [37]. The intact gut barrier controls the entry of dietary antigens and commensal bacteria. Low concentrations of dietary antigens do not normally induce local inflammation but rather lead to specific unresponsiveness, a process called oral tolerance [37]. In healthy individuals, the inductive tissues of the gut normally maintain an immunosuppressive, Th2predominant environment. This is not the case in patients with coeliac disease, the prototype wheat-induced immune disorder, which involves IFN- $\gamma$-related damage to the gut 
$[38,39]$. The present study shows that this is also the case in young BBdp rats. Moreover, these animals display several signs of gut damage including a mild coeliac-like enteropathy [10], decreased disaccharidase activity [40] decreased mucin content [14, 47], and increased gut permeability to FITC-conjugated dextran $4000[14,47]$ and mannitol [11].

Th1/Th2 differentiation involves a balance between Th1-specific T-bet and Th2-specific Gata3 expression [19, $41,42]$. In the present study, measurement of T-bet and Gata3 expression immediately upon excision of the tissues revealed a decrease in the expression of Gata3 and no change in the expression of T-bet, suggesting that, in vivo, the MLN of young BBdp rats display a Th1 bias that is the result of a Th2 deficit rather than the increased production of the Th1 controller, T-bet. The Th1-promoting environment prevailed as early as 1 week after weaning (Fig. 1). This suggests that the MLN cells had already been stimulated in vivo and were primed to favour differentiation towards Th1 cells when pancreatic inflammation was minimal or absent. The low expression of this Th2 signal is consistent with the report that young children with islet antibodies showed decreased production of the Th2 cytokine IL-4 in response to tetanus toxoid and rubella [43]. MLN cells were analysed for the presence of IFN- $\gamma^{+}$ Th1 cells 2 weeks after the appearance of the increased T-bet : Gata3 ratio to allow sufficient exposure to dietary antigens to ensure full Th1 polarisation of naïve $T$ cells [19]. The MLN of BBdp rats, but not BBc animals, displayed a high frequency of $\mathrm{CD}^{+} \mathrm{CD}^{+}{ }^{+} \mathrm{IFN}-\gamma^{+}$cells (Fig. 2). This increase was blocked in HC-fed BBdp rats, consistent with the finding that BBdp MLNs and pancreatic lymph nodes are centres of unusually high mitotic activity, which is blocked in rats fed an $\mathrm{HC}$ diet [44, 45].

Based on the report that wheat protein-based diets promote the development of diabetes in BBdp rats [4] and the early development of a Th1 bias in the MLN of wheatfed rats in the present study, we investigated whether there was an increased prevalence of wheat protein-reactive immune cells in the GALT of BBdp rats around the age when diabetes first begins to appear. CFDA-SE labelling and flow cytometry [24] were used to analyse T cell proliferation in response to wheat protein antigens in rats aged 60 days that had been exposed to the NTP-2000 diet for 5 weeks. This method allows the simultaneous characterisation of proliferating cells and their phenotype. Gatng on total $\mathrm{CD} 4^{+} \mathrm{T}$ cells and the determination of the proliferation of $\alpha \beta-\mathrm{TCR}^{+} \mathrm{CD}^{+}$cells permitted comparisons that were not confounded by BBdp T cell lymphopenia. This analysis revealed a population of wheat protein-specific $\mathrm{CD}^{+} \mathrm{T}$ cells in the MLN of BBdp rats (Fig. 3). These cells were less frequent in the spleen, suggesting that they are activated in the gut and present at lower levels in the systemic immune system. The reasons why the gut of the BBdp rat is a site of wheat protein-induced $\mathrm{CD}^{+} \mathrm{T}$ cell proliferation are not known, but could be related to the low frequency of $\mathrm{CD} 4{ }^{+} \mathrm{CD} 25^{+} \mathrm{T}$ regulatory cells and the increased frequency of antigen-presenting cells (Fig. 5) [46].
The development of enteropathy in the BBdp gut by as early as 30 days [10] could set the stage for the continuing inflammatory damage and increased permeability [11, 47] that has been linked to diabetes outcome [48] and is reported to be diet-modifiable [14, 47]. A leaky gut could permit the entry of unusually large amounts of soluble dietary wheat antigens through the mucosal barrier. Analysis of the phenotype of the cell populations in the draining MLN showed a disproportionately high frequency of antigen-presenting dendritic cells (Fig. 4), which could favour the presentation of dietary antigens to naïve $\mathrm{T}$ cells, leading to their maturation into Th1 cells and increased proliferation (Fig. 3). An environment loaded with wheat antigens could also promote the maturation of dendritic cells, as reported recently in wheat-treated dendritic cells from BALB/c mice [49].

The present findings are the first to indicate a dietspecific activation of Th1 lymphocytes in the GALT of BBdp rats. $\mathrm{CD}^{+} \mathrm{T}$ cells are required for the initiation and promotion of diabetes development in the BBdp rat [50]. $\mathrm{CD} 8^{+} \mathrm{T}$ cells are also required as effectors, but are almost absent in BBdp rats [51], and showed little response to wheat protein antigens in the present study (Fig. 3). It may be speculated that Th1 cytokine-producing cells are activated in association with the coeliac-like proinflammatory state of the gut [10] and could play a role in the dietary modification of type 1 diabetes. We did not perform adoptive transfer studies because of the difficulty in obtaining sufficient numbers of cells from the MLN of BBdp rats, which are T cell lymphopenic. However, it has been reported that MLN cells can transfer diabetes in NOD mice [52], and MLN lymphocytes have been shown to traffic through the pancreas [53].

In summary, there was a diet-related Th1 bias in the GALT of BBdp rats, as indicated by an increased T-bet : Gata-3 ratio and a high frequency of IFN $-\gamma^{+}$Th1 cells in freshly isolated MLN from NTP-2000-fed animals. IFN $-\gamma^{+}$ Th1 cells were less frequent in HC-fed BBdp rats and in BBc animals. MLN cells from NTP-2000-fed BBdp rats were stimulated to proliferate in vitro in the presence of increasing amounts of wheat antigens, indicating a specific response that was absent in corresponding controls. This occurred at ages when islet inflammation is minimal or absent. Given the T cell lymphopenia in the BBdp rat, it is remarkable that such a large number of cells responded. We suggest that this process could be the result of a combination of factors, including entry of large amounts of soluble wheat antigens through a leaky gut barrier into the MLN, where a proinflammatory Th1 microenvironment prevails, in association with low numbers of $\mathrm{T}$ regulatory cells and increased antigen-presenting cells. Thus, the main inductive site for immune reactions in the gut, the MLN, contains wheat-activated Th1 cells whose frequency and proliferative capacity is increased in diabetes-prone rats fed a mainly wheat-based NTP-2000 diet, but is low in animals fed an $\mathrm{HC}$ diet. 
Acknowledgements H. Chakir and D. E. Lefebvre contributed equally to this work. We are grateful to H. Gruber, A. Zafer, J. Crookshank and E. Faller for technical assistance; to M. Parenteau for assistance with flow cytometry; to J. Souligny and D. Patry for supplying and caring for the animals; and to the Animal Resources Division, Health Canada for maintaining the rat colony. These studies were supported by the Juvenile Diabetes Research Foundation (JDRF), the Canadian Institutes of Health Research (CIHR), the Ontario Research and Development Challenge Fund, the Canada Foundation for Innovation, and Health Canada.

\section{References}

1. Beales PE, Elliott RB, Flohe $\mathrm{S}$ et al (2002) A multi-centre, blinded international trial of the effect of $A(1)$ and $A(2)$ betacasein variants on diabetes incidence in two rodent models of spontaneous Type I diabetes. Diabetologia 45:1240-1246

2. Akerblom HK, Knip M (1998) Putative environmental factors in Type 1 diabetes. Diabetes Metab Rev 14:31-67

3. Rao GN (1996) New diet (NTP-2000) for rats in the National Toxicology Program toxicity and carcinogenicity studies. Fundam Appl Toxicol 32:102-108

4. MacFarlane AJ, Burghardt KM, Kelly J et al (2003) A type 1 diabetes-related protein from wheat (Triticum aestivum). cDNA clone of a wheat storage globulin, Glb1, linked to islet damage. J Biol Chem 278:54-63

5. Hoorfar J, Buschard K, Dagnaes-Hansen F (1993) Prophylactic nutritional modification of the incidence of diabetes in autoimmune non-obese diabetic (NOD) mice. Br J Nutr 69:597-607

6. Funda DP, Kaas A, Bock T, Tlaskalova-Hogenova H, Buschard K (1999) Gluten-free diet prevents diabetes in NOD mice. Diabetes Metab Res Rev 15:323-327

7. Schmidt S, Koczwara K, Schwinghammer S, Lampasona V, Ziegler A-G, Bonifacio E (2004) Delayed exposure to wheat and barley proteins reduces diabetes incidence in non-obesediabetic mice. Clin Immunol 111:108-118

8. Ziegler AG, Schmid S, Huber D, Hummel M, Bonifacio E (2003) Early infant feeding and risk of developing type 1 diabetes-associated autoantibodies. JAMA 290:1721-1728

9. Norris JM, Barriga K, Klingensmith G et al (2003) Timing of initial cereal exposure in infancy and risk of islet autoimmunity. JAMA 290:1713-1720

10. Graham S, Courtois P, Malaisse WJ, Rozing J, Scott FW, Mowat AM (2004) Enteropathy precedes type 1 diabetes in the BB rat. Gut 53:1437-1444

11. Meddings JB, Jarand J, Urbanski SJ, Hardin J, Gall DG (1999) Increased gastrointestinal permeability is an early lesion in the spontaneously diabetic BB rat. Am J Physiol 276:G951-G957

12. Hardin JA, Donegan L, Woodman RC, Trevenen C, Gall DG (2002) Mucosal inflammation in a genetic model of spontaneous type I diabetes mellitus. Can J Physiol Pharmacol 80:10641070

13. Courtois P, Sener A, Scott FW, Malaisse WJ (2004) Peroxidase activity in the intestinal tract of Wistar-Furth, BBc and BBdp rats. Diabetes Metab Res Rev 20:305-314

14. Malaisse WJ, Courtois P, Scott FW (2004) Insulin-dependent diabetes and gut dysfunction: the BB rat model. Horm Metab Res 36:585-594

15. Westerholm-Ormio M, Vaarala O, Pihkala P, Ilonen J, Savilahti E (2003) Immunologic activity in the small intestinal mucosa of pediatric patients with type 1 diabetes. Diabetes 52:2287-2295

16. Secondulfo M, Iafusco D, Carratu R et al (2004) Ultrastructural mucosal alterations and increased intestinal permeability in non-celiac, type I diabetic patients. Dig Liver Dis 36:35-45

17. Carratu R, Secondulfo M, de Magistris L et al (1999) Altered intestinal permeability to mannitol in diabetes mellitus type I. J Pediatr Gastroenterol Nutr 28:264-269
18. Damci T, Nuhoglu I, Devranoglu G, Osar Z, Demir M, Ilkova $\mathrm{H}$ (2003) Increased intestinal permeability as a cause of fluctuating postprandial blood glucose levels in Type 1 diabetic patients. Eur J Clin Invest 33:397-401

19. Chakir H, Wang H, Lefebvre DE, Webb J, Scott FW (2003) Tbet/GATA-3 ratio as a measure of the Th1/Th2 cytokine profile in mixed cell populations: predominant role of GATA-3. J Immunol Methods 278:157-169

20. Caraher EM, Parenteau M, Gruber H, Scott FW (2000) Flow cytometric analysis of intracellular IFN-gamma, IL-4 and IL-10 in $\mathrm{CD}^{+} 4^{+}$T-cells from rat spleen. J Immunol Methods 244: $29-40$

21. Arentz-Hansen EH, McAdam SN, Molberg O, Kristiansen C, Sollid LM (2000) Production of a panel of recombinant gliadins for the characterisation of $\mathrm{T}$ cell reactivity in coeliac disease. Gut 46:46-51

22. Bradford MM (1976) A rapid and sensitive method for the quantitation of microgram quantities of protein utilizing the principle of protein-dye binding. Anal Biochem 72:248-254

23. Szabo SJ, Kim ST, Costa GL, Zhang X, Fathman CG, Glimcher LH (2000) A novel transcription factor, T-bet, directs Th1 lineage commitment. Cell 100:655-669

24. Turcanu V, Maleki SJ, Lack G (2003) Characterization of lymphocyte responses to peanuts in normal children, peanutallergic children, and allergic children who acquired tolerance to peanuts. J Clin Invest 111:1065-1072

25. Kolb H, Worz-Pagenstert U, Kleemann R, Rothe H, Rowsell P, Scott FW (1996) Cytokine gene expression in the BB rat pancreas: natural course and impact of bacterial vaccines. Diabetologia 39:1448-1454

26. Scott FW, Cloutier HE, Kleemann R et al (1997) Potential mechanisms by which certain foods promote or inhibit the development of spontaneous diabetes in BB rats: dose, timing, early effect on islet area, and switch in infiltrate from Th1 to Th2 cells. Diabetes 46:589-598

27. Rabinovitch A, Suarez-Pinzon W, El-Sheikh A, Sorensen O, Power RF (1996) Cytokine gene expression in pancreatic isletinfiltrating leukocytes of BB rats: expression of Th1 cytokines correlates with beta-cell destructive insulitis and IDDM. Diabetes 45:749-754

28. Zipris D, Greiner DL, Malkani S, Whalen B, Mordes JP, Rossini AA (1996) Cytokine gene expression in islets and thyroids of BB rats. IFN-gamma and IL-12p40 mRNA increase with age in both diabetic and insulin-treated nondiabetic BB rats. J Immunol 156:1315-1321

29. Prud'homme G, Fuks A, Colle E, Seemayer T, Guttmann R (1984) Immune dysfunction in diabetes-prone BB rats. Interleukin 2 production and other mitogen-induced responses are suppressed by activated macrophages. J Exp Med 159:463-478

30. Scott FW, Sarwar G, Cloutier HE (1988) Diabetogenicity of various protein sources in the diet of the diabetes-prone BB rat. Adv Exp Med Biol 246:277-285

31. Scott FW (1996) Food-induced type 1 diabetes in the BB rat. Diabetes Metab Rev 12:341-359

32. Arif S, Tree TI, Astill TP et al (2004) Autoreactive T cell responses show proinflammatory polarization in diabetes but a regulatory phenotype in health. J Clin Invest 113:451-463

33. Vaarala O (2002) The gut immune system and type 1 diabetes. Ann N Y Acad Sci 958:39-46

34. Kolb H, Pozzilli P (1999) Cow's milk and type I diabetes: the gut immune system deserves attention. Immunol Today 20: $108-110$

35. Paronen J, Klemetti P, Kantele JM et al (1997) Glutamate decarboxylase-reactive peripheral blood lymphocytes from patients with IDDM express gut-specific homing receptor alpha4beta7integrin. Diabetes 46:583-588

36. Savilahti E, Ormala T, Saukkonen T et al (1999) Jejuna of patients with insulin-dependent diabetes mellitus (IDDM) show signs of immune activation. Clin Exp Immunol 116:70-77 
37. Mowat AM (2003) Anatomical basis of tolerance and immunity to intestinal antigens. Nat Rev Immunol 3:331-341

38. Nilsen EM, Jahnsen FL, Lundin KE et al (1998) Gluten induces an intestinal cytokine response strongly dominated by interferon gamma in patients with celiac disease. Gastroenterology 115:551-563

39. Monteleone I, Monteleone G, Del Vecchio Blanco G, (2004) Regulation of the T helper cell type 1 transcription factor T-bet in coeliac disease mucosa. Gut 53:1090-1095

40. Courtois P, Sener A, Scott FW, Malaisse WJ (2004) Disaccharidase activity in the intestinal tract of Wistar-Furth, diabetesresistant and diabetes-prone BioBreeding rats. Br J Nutr 91: 201-209

41. Neurath MF, Finotto S, Glimcher LH (2002) The role of Th1/ Th2 polarization in mucosal immunity. Nat Med 8:567-573

42. Neurath MF, Weigmann B, Finotto S et al (2002) The transcription factor $\mathrm{T}$-bet regulates mucosal $\mathrm{T}$ cell activation in experimental colitis and Crohn's disease. J Exp Med 195:11291143

43. Schmid S, Molteni A, Fuchtenbusch M, Naserke HE, Ziegler AG, Bonifacio E (2002) Reduced IL-4 associated antibody responses to vaccine in early pre-diabetes. Diabetologia 45:677685

44. Olivares E, Ladriere L, Laghmich A, Sener A, Malaisse WJ, Scott FW (1999) Effects of a protective hydrolyzed casein diet upon the metabolic and secretory responses of pancreatic islets to IL-1beta, cytokine production by mesenteric lymph node cells, mitogenic and biosynthetic activities in Peyer's patch cells, and mitogenic activity in pancreatic lymph node cells from control and diabetes-prone BB rats. Mol Genet Metab 68:379-390

45. Malaisse WJ, Olivares E, Laghmich A, Ladriere L, Sener A, Scott FW (2000) Feeding a protective hydrolysed casein diet to young diabetic-prone $\mathrm{BB}$ rats affects oxidation of $\mathrm{L}\left[\mathrm{U}_{-}{ }^{14} \mathrm{C}\right]$ glutamine in islets and Peyer's patches, reduces abnormally high mitotic activity in mesenteric lymph nodes, enhances islet insulin and tends to normalize NO production. Int $\mathrm{J}$ Exp Diabetes Res 1:121-130
46. Poussier P, Ning T, Murphy T, Dabrowski D, Ramanathan $\mathrm{S}$ (2004) Impaired development of regulatory $\mathrm{CD} 4^{+} \mathrm{CD} 25^{+} \mathrm{Foxp}^{+} \mathrm{T}$ cells contributes to the spontaneous onset of diabetes in $\mathrm{BB}$ rats. Clin Invest Med 27:169A

47. Courtois P, Nsimba G, Jijakli H, Sener A, Scott FW, Malaisse WJ (2005) Gut permeability and intestinal mucins, invertase, and peroxidase in control and diabetes-prone BB rats fed either a protective or a diabetogenic diet. Dig Dis Sci 50:266-275

48. Watts T, Berti I, Sapone A et al (2005) Role of the intestinal tight junction modulator zonulin in the pathogenesis of type I diabetes in BB diabetic-prone rats. Proc Natl Acad Sci U S A 102:2916-2921

49. Nikulina M, Habich C, Flohe SB, Scott FW, Kolb H (2004) Wheat gluten causes dendritic cell maturation and chemokine secretion. J Immunol 173:1925-1933

50. Whalen BJ, Greiner DL, Mordes JP, Rossini AA (1994) Adoptive transfer of autoimmune diabetes mellitus to athymic rats: synergy of $\mathrm{CD}^{+}$and $\mathrm{CD} 8^{+} \mathrm{T}$ cells and prevention by $\mathrm{RT} 6^{+}$ T cells. J Autoimmun 7:819-831

51. Edouard P, Hiserodt JC, Plamondon C, Poussier P (1993) CD8 ${ }^{+}$ T-cells are required for adoptive transfer of the $\mathrm{BB}$ rat diabetic syndrome. Diabetes 42:390-397

52. Hanninen A, Jaakkola I, Jalkanen S (1998) Mucosal addressin is required for the development of diabetes in nonobese diabetic mice. J Immunol 160:6018-6025

53. Whalen BJ, Love LC, Mordes JP, Rossini AA, Greiner DL (1999) Intravital dye-labeled diabetogenic rat T cells retain dye, home to the pancreas, and induce diabetes. Transplant Proc 31:1611-1614

54. Maurano F, Mazzarella G, Luongo D et al (2005) Small intestinal enteropathy in non-obese diabetic mice fed a diet containing wheat. Diabetologia 48:931-937 